\title{
SEASONAL FOLIAGE DYNAMICS OF MANGROVE Bruguiera gymnorrhiza (L.) lamk. IN A SUBTROPICAL REGION, MANKO WETLAND, OKINAWA ISLAND, JAPAN
}

\author{
S. Sharma ${ }^{1 *}$, A.T.M. Rafiqul Hoque ${ }^{2}$, K. Analuddin $^{3}$ and A. Hagihara ${ }^{4}$ \\ ${ }^{1}$ Graduate School of Engineering and Science, University of the Ryukyus, Okinawa, Japan \\ ${ }^{2}$ Institute of Forestry and Environmental Sciences, Chittagong University, Chittangong, Bangladesh \\ ${ }^{3}$ Department of Biology, Faculty of Mathmatics and Natural Sciences, Haluoleo University, Kendari \\ Indonesia, \\ ${ }^{4}$ Faculty of Science, University of the Ryukyus, Okinawa, Japan \\ E-mail-mangrove_coral@yahoo.co.in, Tel-+81-80-4310-3681, Fax- ++ 94116789999
}

\begin{abstract}
Abstrct
In case of mangroves, little information is available on seasonal crown leaf area growth and leaf survival. Therefore, it is necessary to investigate the dynamics of crown foliage to understand the productivity of mangroves. The present study describes the crown foliage dynamics of Bruguiera gymnorrhiza (L.) Lamk., Okinawa Island, Japan, which is the northern limit of its distribution. This study was carried out from April 2008 to March 2009. The crown foliage dynamics includes the leaf recruitment and survival. The production and fall of leaves were investigated by a direct observation of a sample tree of $B$. gymnorrhiza as well as by an indirect observation of litterfall measurement. The numbers of surviving and dying new leaves were totaled monthly. Newly flushed leaves occurred successively throughout the year, with a maximum in July and a minimum in January. The highest leaf death was in June, whereas the lowest was in December. The crown leaf area was almost stable throughout the year, having a peak in December. The homeostatic control of the crown foliage area may also be accompanied by the regulation of leaf recruitment and death. Therefore, the present results suggest the existence of integrated mechanisms between the internal and external factors maintain the crown foliage area.
\end{abstract}

Keywords: Crown leaf area, Bruguiera gymnorrhiza, Leaf area growth, Leaf recruitment, litterfall

\section{INTRODUCTION}

Studies of canopy foliage dynamics are, necessary in evaluating forest productivity (Osada et al., 2001). However, these studies generally require either expensive or labor intensive method of accessing tall trees (Moffett and Lowman, 1995), and thus simpler methods are needed in order to study these characteristics in various forests. Since leaf area plays an important role in photosynthesis, light interception, water and nutrient use, crop growth, and yield potential (Aase, 1978; Williams, 1987), a simple, rapid, accurate, and non-destructive method for the estimation of leaf area and plant growth rate (Montero et al., 2000) is needed. To monitor continuous changes in leaf area and the subsequent growth, a modeling approach is essential. Since leaf development has a strong relationship with plant growth, knowledge of the change in leaf area may be useful for estimating plant growth. Habitat resource availability has also been postulated as a driving force for the evolution of plant characteristics, including leaf lifespan (Coley et al., 1985). Resource limited habitats favor plants with inherently slow growth; low photosynthetic rates, nutrient contents and SLA; long

Proceedings of the $15^{\text {th }}$ International Forestry and Environment Symposium, 26-27 November 2010.

Published by Department of Forestry and Environmental Science, University of Sri Jayewardenepura, Sri Lanka. 
leaf lifetime; and large investments in antiherbivore defenses, with the reverse more likely for resource-rich environments. Accordingly, leaf area growth and leaf survival are important factors that determine how plants will function.

The production and fall of mangrove leaves can be investigated by direct observation of sample tree and by indirect observation of litterfall measurement. Many studies have documented mangrove litterfall to assess productivity, because the litterfall helps maintain the productivity of mangrove and the adjacent ecosystems. However, few studies have documented the seasonal patterns in the production and fall of mangrove leaves using litterfall, in which the occurrence of stipules is of special interest since the stipules protecting the shoot's terminal bud are a reliable indicator of new leaf formation (Mehlig, 2006).

Numerous studies have focused on leaf growth and leaf survival in terrestrial plants (e.f. Reich et al., 1991; Lafarge and Tardieu, 2002; Dosio et al., 2003). However, little information is available on seasonal leaf area growth and leaf survival in mangroves (Analuddin et al., 2009). Therefore, the objectives of this study is to elucidate the crown foliage dynamics of mangrove Bruguiera gymnorrhiza in terms of leaf recruitment, area growth and survival on the basis of the direct observation.

\section{MATERIALS AND METHODS}

\subsection{STUDY AREA}

The study was conducted in a mangrove forest $\left(26^{\circ} 11^{\prime} \mathrm{N}\right.$ and $\left.127^{\circ} 40^{\prime} \mathrm{E}\right)$ of Manko Wetland, Okinawa Island, Japan (Figure 1). This wetland is an important area for migratory birds and has been registered as the RAMSAR site since 1999, and has been also designated as a special wildlife sanctuary by the Ministry of the Environment, Japan. The warmth index (Kira 1991), based on the data of 1991-2000 obtained from the Okinawa Meteorological Observatory, Naha, Okinawa, was $217.8^{\circ} \mathrm{C}$ month, indicating that this area belongs to the subtropical region.

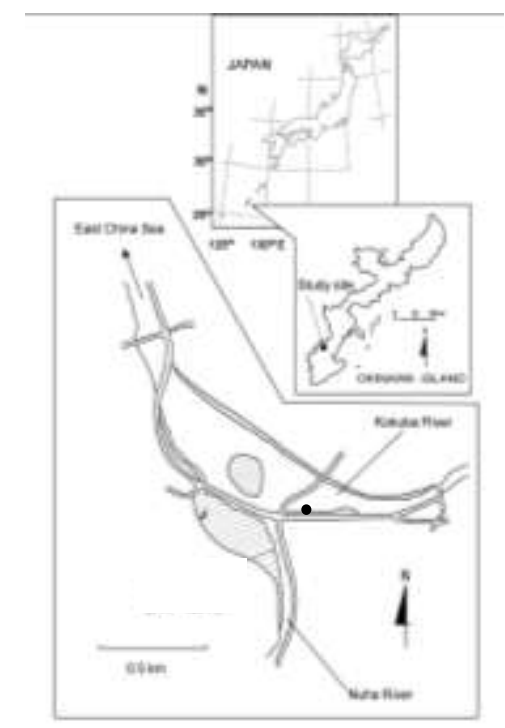

Figure 1: Location of the study area. The hatched area indicates the mangrove area.

Proceedings of the $15^{\text {th }}$ International Forestry and Environment Symposium, 26-27 November 2010.

Published by Department of Forestry and Environmental Science, University of Sri Jayewardenepura, Sri Lanka. 


\subsection{PLOT ESTABLISHMENT, TREE CENSUS AND LITTERFALL COLLECTION}

Four subplots of $4 \mathrm{~m} \mathrm{x} 4 \mathrm{~m}$ were established in a monospecific B. gymnorrhiza stand. All individuals in the subplots were counted and numbered. The canopy of the monospecific $B$. gymnorrhiza stand is completely closed, and mean tree density, mean $H$, mean $D_{0.1 \mathrm{H}}$ and mean DBH in March 2009 were $1.80 \mathrm{~m}^{-2}, 3.00 \pm 0.06$ (SE) $\mathrm{m}, 4.76 \pm 0.15$ (SE) $\mathrm{cm}$ and $2.85 \pm$ 0.09 (SE) cm, respectively. The litterfall traps were emptied monthly from April 2008 to March 2009 and the litterfall was sorted into leaves, stipules, flowers, propagules and branches. The sorted litterfalls were dried to a constant mass at $80^{\circ} \mathrm{C}$ over a $48 \mathrm{~h}$ period, and then weighed.

\subsection{CLIMATIC CONDITIONS}

Figure 2 shows the monthly changes in mean air temperature and mean air vapor pressure deficit, VPD $\left(=\frac{100 \cdot \mathrm{VP}}{\mathrm{RH}}-\mathrm{VP}\right)$, where VP is monthly vapor pressure and $\mathrm{RH}$ is monthly relative humidity during the study period of April 2008 to March 2009 (data from Okinawa Meteorological Observatory). The highest monthly mean air temperature and VPD were $29.4^{\circ} \mathrm{C}$ in July and $11.5 \mathrm{hPa}$ in July, respectively. The lowest monthly mean air temperature and VPD were $16.7^{\circ} \mathrm{C}$ in January and $6.44 \mathrm{hPa}$ in March, respectively. Annual rainfall was $1417.5 \mathrm{~mm} \mathrm{yr}^{-1}$.

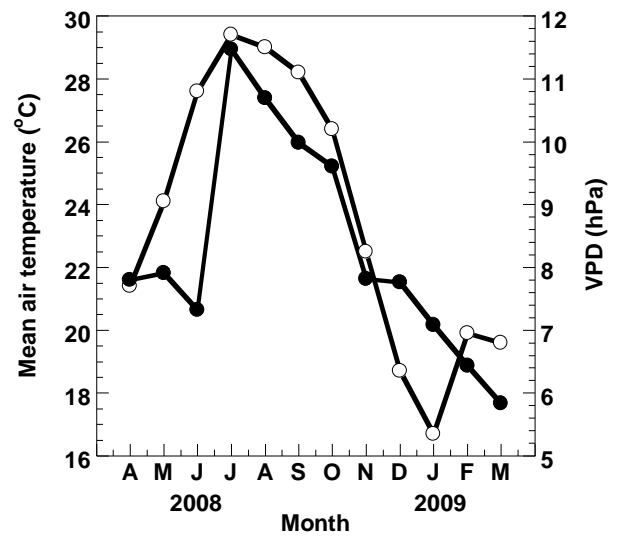

Proceedings of the $15^{\text {th }}$ International Forestry and Environment Symposium, 26-27 November 2010.

Published by Department of Forestry and Environmental Science, University of Sri Jayewardenepura, Sri Lanka. 
leaf area were estimated using the allometric relationship of leaf area $u\left(\mathrm{~cm}^{2}\right)$ to leaf length $l$ $(\mathrm{cm})$ times width $w(\mathrm{~cm})$, as shown in Figure 3. This allometric relationship has the form:

$u=0.6985(l \cdot w)^{1.0001}$

The area of old leaves existing at the beginning of april 2008 was estimated on the assumption that the old leaves consist of leaves flushed in different seasons, and have already reached their maximum areas. Thus, the area of the old leaves was calculated by multiplying the mean of the maximum area of leaves flushed in different seasons and the number of old leaves remaining in each month. In addition, leaf recruitment and death were estimated indirectly on the basis of stipule and leaf litterfalls using litter traps.

\section{RESULTS}

\subsection{LEAF RECRUIT AND DEATH}

Figure 4 represents the seasonal changes in leaf recruitment and death of the sample tree (direct observation) and in stipule and leaf litterfalls from the sub-plots (indirect observation). The maximum of leaf recruitment (Figure 4a) occurred in July and the maximum of stipule litterfall (Figure 4b) occurred in July, while the maximum of leaf death (Figure 4a) occurred in June and the maximum of leaf litterfall (Figure 4b) occurred in June. The leaf recruitment and the stipule litterfall reached a minimum in January, while the leaf death and the leaf litterfall reached a minimum in December. These results suggest that the seasonal patterns of stipule and leaf litterfall reflect well the patterns of leaf recruitment and death based on the direct observation.

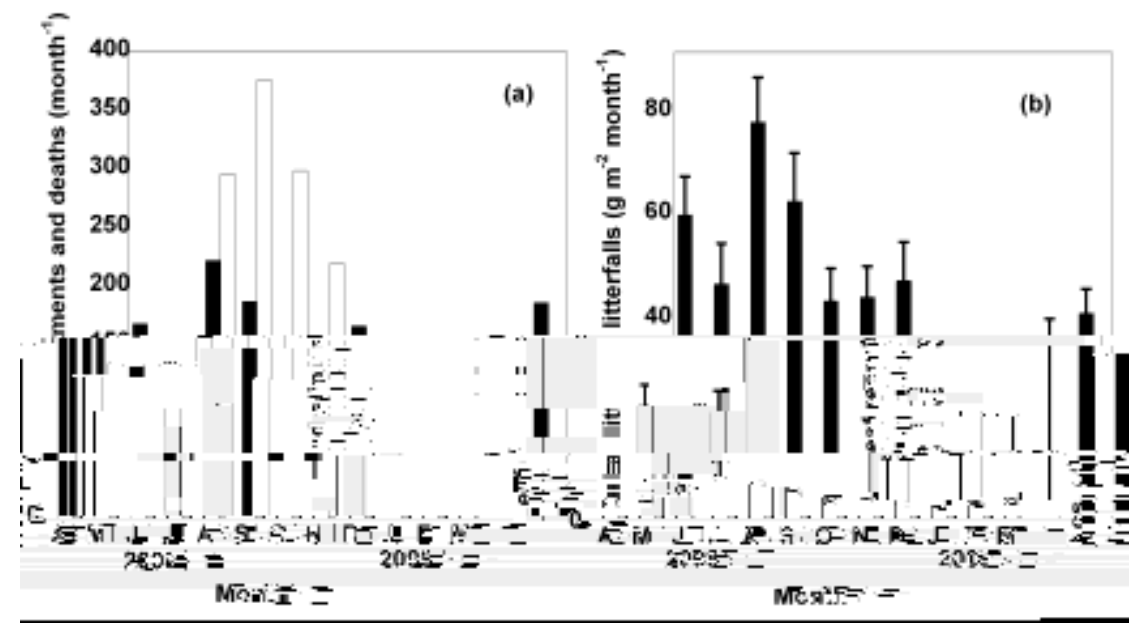

Figure 4: Seasonal variations in leaf recruit (open columns) and leaf death (closed columns) of a sample tree (a) and in stipule (open columns) and leaf (closed columns) litterfalls in the subplots (b). Litterfall data are shown by mean \pm SE. 


\subsection{SEASONAL PATTERN OF LEAF AREA GROWTH}

Figures 7 depicts the mean area growth of leaves flushed in different months. Although the growth of leaf area was different among leaves flushed in different months, the growing area of a single leaf is well described by the logistic growth curve :

$u=\frac{U}{1+k \cdot \mathrm{e}^{-\lambda \cdot t}}$

where $U, \lambda$ and $k$ are the maximum leaf area, intrinsic rate of increase and constant, respectively. Assuming Eq. (2), the half-expansion period $t^{*}$, which is the time necessary for the leaf to reach one-half of its $U$, is defined as follows:

$t^{*}=\frac{\ln k}{\lambda}$

As shown in Figure 6, maximum leaf area $U$, half-expansion period $t^{*}$ and intrinsic rate of increase $\lambda$ varied significantly among seasons. The $U$ value was low for the summer and winter seasons, while it was highest for the autumn and spring seasons (Figure 6a). The $t^{*}$ value was significantly longer in the winter than the the summer $(p>0.68)$, the autumn $(p>$ $0.30)$ and the spring $(p>0.35)$ (Figure $6 \mathrm{~b})$. The $\lambda$ value was significantly low in the winter and high in the autumn $(p>0.19)$ as compared with the the spring $(p>0.49)$. However, $\lambda$ value of the winter showed a significant difference with the other seasons. On the other hand, the summer and the autumn did not show a significant difference (Figure $6 \mathrm{c}$ ). It can therefore be concluded that leaves flushed in the autumn grow faster initially and attain their maximum leaf area sooner than those flushed in the winter.

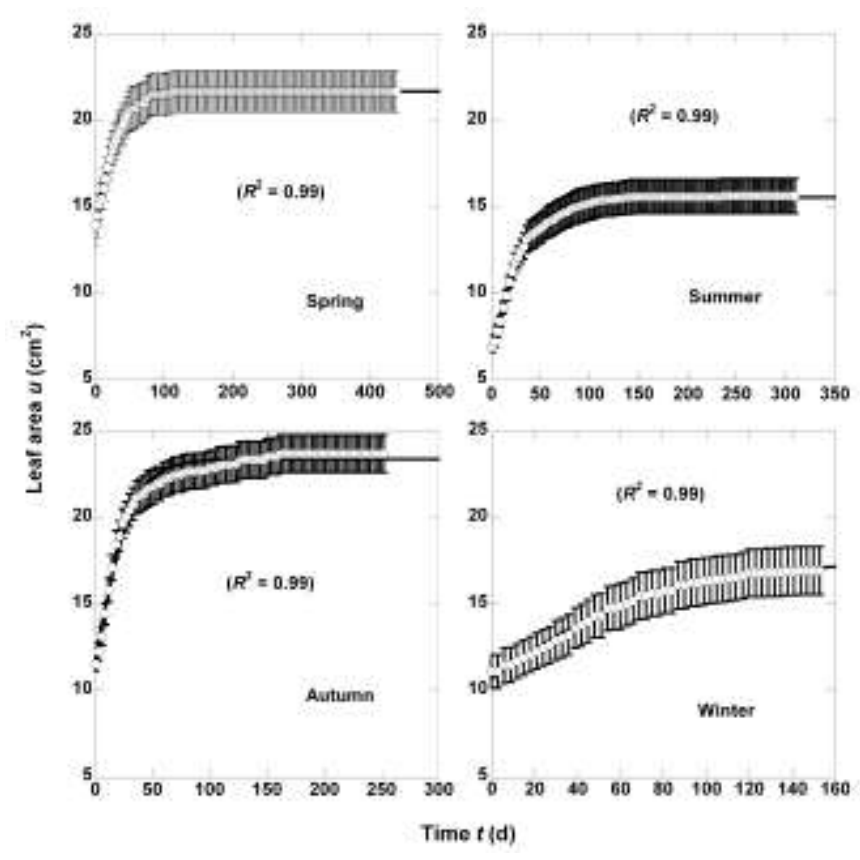

Figure 5: Area growth $u$ of leaves with the progress of time $t$ in different months. The curves are given by Eq. (2). Data are shown with mean \pm SE. 


\subsection{SEASONAL CHANGE IN CROWN LEAF AREA}

Crown leaf area $C(t)$ at a given month $t$ was calculated discretely from the following equation:

$C(t)=\sum_{\tau=0}^{\mathrm{t}} N_{\tau} \cdot S_{\tau}(t-\tau) \cdot u_{\tau}(t-\tau) \quad(t \geq \tau)$,

where $N_{\tau}$ is the number of leaves flushed at a certain month $\tau$ before the month $t$ (Figure 4a), $S_{\tau}(t-\tau)$ is the probability that the leaves will survive during a period of $t-\tau$ month, and $u_{\tau}(t-\tau)$ is the mean leaf area of the leaves just after the period of $t-\tau$ month (Figure 5).
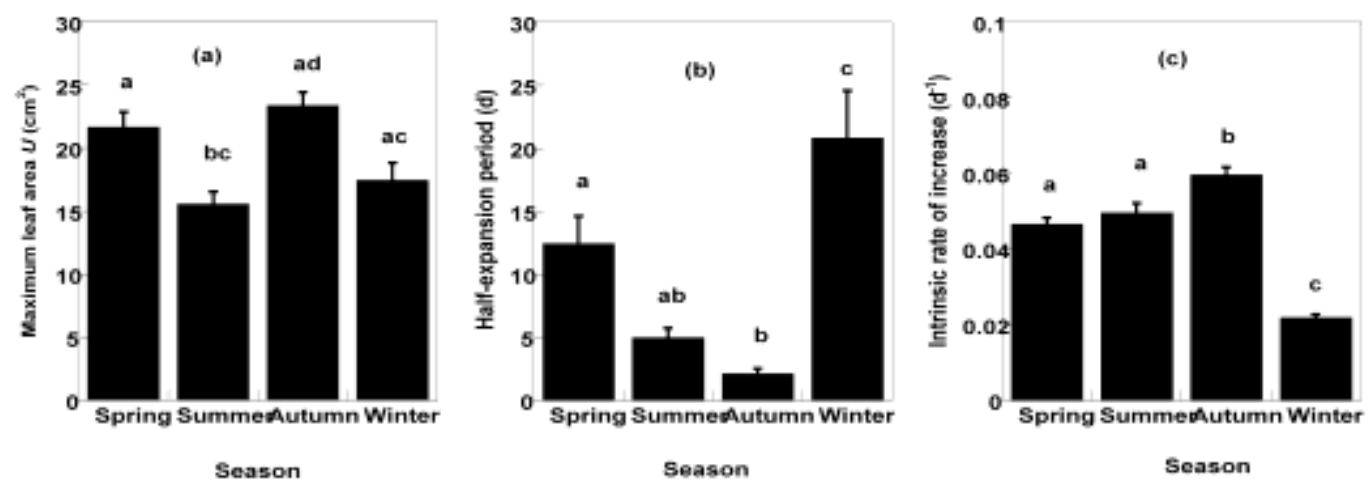

Figure 6: Seasonal variations of maximum leaf area $U$ (a), half-expansion period $t^{*}$ (b) and intrinsic rate of increase $\lambda(\mathrm{c})$. Data are shown with mean $\pm \mathrm{SE}$. The same letters stand for no significant difference at a sifnificance level of 0.05 .

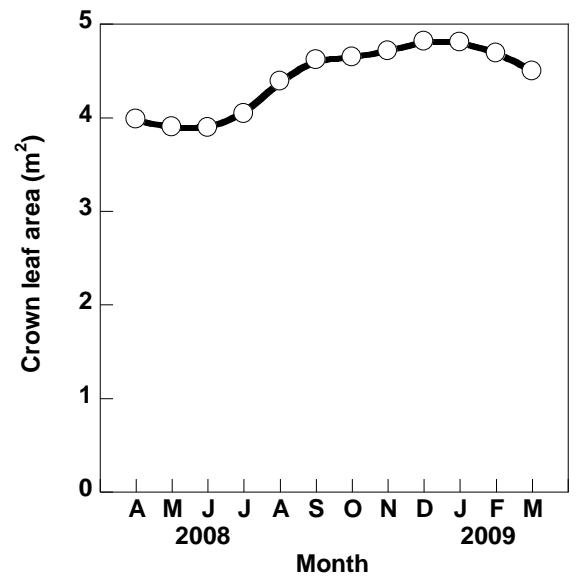

Figure 7: Seasonal change in crown leaf area.

\section{DISCUSSION}

Newly flushed leaves appeared successively throughout the year, though there is a seasonal change with a maximum in the summer and a minimum in the winter (Fig. 4). The number of leaves recruited in the summer represented $48.0 \%$ of the annual total, whereas $13.6 \%$ were recruited in the winter. Gwada et al. (2000) reported a similar seasonal trend in Kandelia obovata leaf production at Sashiki, Okinawa Island, Japan. 
The growth pattern of leaves varied with seasons (Figure 5). The maximum leaf area was almost the same in all the seasons except for the summer (Figure 6a). However, maximum leaf area depends on the position of the leaves. Although leaf growth pattern is known to be affected by various environmental factors, such as temperature, water availability, irradiance, mineral nutrition and $\mathrm{CO}_{2}$ concentration.

The half-expansion period (Figure 6b) and the intrinsic rate of increase (Figure 6c) were respectively longer and lower in the winter than in the other seasons. This is because that the leaves of B. gymnorrhiza already grew inside the bud. Leaves flushed in the other seasons grew faster initially and attained their maximum leaf area sooner than those flushed in the winter. This may be due to the differences in temperature and VPD between the winter and the other seasons (Figure 2). Lafarge and Tardieu (2002) reported that high air temperature and VPD had a detrimental effect on leaf elongation of a sorghum cultivar. Thus, the shorter half-expansion period of summer leaves is probably essential for reducing the environmental stresses of high temperature and VPD in the summer. On the other hand, the longer halfexpansion period of winter leaves may be caused by lower temperature and VPD in the winter. However, the larger area of winter leaves may compensate their amount of carbon uptake, which is lower in the winter. Ferris et al. (2001) suggested that leaf area can enhance the opportunity for carbon uptake, albeit at the cost of a greater demand for water.

In contrast to the seasonal fluctuation of leaf area growth, the crown leaf area was almost stable throughout the year (Figure 7), as if homeostatic control is likely to function, though leaves composing crown showed a seasonally dependent growth pattern. Equation (4) states that crown leaf area $C(t)$ is determined by leaf recruitment $N_{\tau}$, leaf death $S_{\tau}(t-\tau)$ and leaf area growth $u_{\tau}(t-\tau)$. The present result suggests that newly flushed leaves and their area growth contribute to an increase in crown leaf area. The crown leaf area gradually increased from April to October, April to December and July to June, respectively, because the number of leaves recruitment was much higher than that of leaves dying in the same period.

\section{CONCLUSION}

Newly flushed leaves appeared successively throughout the year, though there is a seasonal change with a maximum in the summer and a minimum in the winter. The growth pattern of leaves varied with seasons. The maximum leaf area was highest in the winter than summer. However, maximum leaf area depends on the position of the leaves. The half-expansion period and the intrinsic rate of increase were respectively longer and lower in the winter than in the other seasons for B. gymnorrhiza. The crown leaf area was almost stable throughout the year, as if homeostatic control is likely to function, though leaves composing crown showed a seasonally dependent growth pattern.

\section{ACKNOWLEDGEMENTS}

We are grateful to our colleagues, Drs. S.M. Feroz and R. Suwa and Messrs. W. Min and R. Deshar, for their cooperation and active participation in the field work. This study was financed in part by a Grant-in-Aid for Scientific Research (No. 20510011) from the Ministry of Education, Culture, Sports, Science and Technology, Japan.

Proceedings of the $15^{\text {th }}$ International Forestry and Environment Symposium, 26-27 November 2010

Published by Department of Forestry and Environmental Science, University of Sri Jayewardenepura, Sri Lanka. 


\section{REFERENCES}

Aase, J.K., 1978. Relationship between leaf area and dry matter in winter wheat. Agron. J. 70, 563565.

Analuddin, K., et al., 2009. Crown foliage dynamics of mangrove Kandelia obovata in Manko Wetland, Okinawa Island, Japan. J. Oceanogr. 65, 121-127.

Coley, P.D., Bryant, J.P., ChapinIII, F.S., 1985. Resource availability and plant antiherbivore defense. Science. 230, 895-899.

Dosio, G.A.A., et al., 2003. A whole-plant analysis of the dynamics of expansion of individual leaves of two sunflower hybrids. J. Exp. Bot. 54, 2541-2552.

Ferris, R., et al., 2001. Leaf area is stimulated in Populus by free air $\mathrm{CO}_{2}$ enrichment (POPFACE), through increased cell expansion and production. Plant Cell Environ. 24, 305-315.

Gwada, P., Tsuchiya, M., Uezu, Y., 2000. Leaf phenological traits in the mangrove Kandelia candel (L.) Druce. Aquat. Bot. 68, 1-14.

Kira, T., 1991. Forest ecosystems of East and Southeast Asia in a global perspective. Ecol. Res. 6, 185200.

Lafarge, T., Tardieu, F., 2002. A model co-ordinating the elongation of all leaves of a sorghum cultivar was applied to both Mediterranean and Sahelian conditions. J. Exp. Bot. 53, 715-725.

Mehlig, U., 2006. Phenology of the red mangrove, Rhizophora mangle L., in the Caeté estuary, Pará, equatorial Brazil. Aquat. Bot. 84, 158-164.

Moffett, M.W., Lowman, M.D., 1995. Canopy access techniques. In: M.D. Lowman, N.M.

Nadkarni, eds. Forest Canopies San Diego: Academic Press, 3-26.

Montero, F.J., et al., 2000. Nondestructive methods to estimate leaf area in Vitis vinifera L. Hort. Sci. 35, 696-698.

Osada, N., et al., 2001. Leaf dynamics and maintenance of tree crowns in a Malaysian rain forest stand. J. Ecol. 89, 774-782.

Reich, P.B., et al., 1991. Leaf lifespan as a determinant of leaf structure and function among 23 Amazonian tree species. Oecologia. 86, 16-24.

Williams, L.E., 1987. Growth of 'Thompson Seedless' grapevines. I. Leaf area development and dry weight distribution. Am. Socie. Hort. Sci. 112, 325-330. 